\title{
Mechanism of the Oxidation of Iron
}

\author{
Minghuan Zhang ${ }^{1, a}$, Qing Shao ${ }^{2, b}$, Lu Yuan ${ }^{3, c}$, Guangwen Zhou ${ }^{3, d}$,
}

\author{
Yiqian Wang ${ }^{1, \mathrm{e}}$ \\ ${ }^{1}$ College of Chemistry, Chemical Engineering and Environmental Engineering, Qingdao University, \\ No. 308 Ningxia Road, Qingdao, 266071, P. R. China \\ ${ }^{2}$ College of Physical Science, Qingdao University, No. 308 Ningxia Road, Qingdao, 266071, P. R. \\ China \\ 3. Department of Mechanical Engineering \& Multidisciplinary Program in Materials Science and \\ Engineering, State University of New York, Binghamton, NY 13902, USA \\ azhangminghuan@126.com, bshaoqing1992@163.com, 'lyuan1@binghamton.edu, \\ 'gzhou@binghamton.edu, eyqwang@qdu.edu.cn
}

Keywords: Oxidation Mechanism, Iron, TEM, SAED

\begin{abstract}
A layered structure of different iron oxides was produced by thermal oxidation of iron. The structure and microstructure of different layers were examined using scanning electron microscopy (SEM) and transmission electron microscopy (TEM). Selected area electron diffraction (SAED) was used to identify the structures of the different oxide layers. Two different structures of $\mathrm{Fe}_{2} \mathrm{O}_{3}$ were found to co-exist. Based on our observation, a possible oxidation mechanism for iron was proposed. The results shed light on the oxidation process of metals and provide insight into the synthesis of iron oxides.
\end{abstract}

\section{Introduction}

Significant research work has been focused on iron and iron oxides because of their wide applications. For example, hematite $\left(\mathrm{Fe}_{2} \mathrm{O}_{3}\right)$ has good semiconducting properties because of its lower band gap $(2.1 \mathrm{eV})$ and is widely used as catalyst [1], gas sensing material [2] and pigments [3]. Magnetite $\left(\mathrm{Fe}_{3} \mathrm{O}_{4}\right)$ is usually used in the field of magnetic recording media and some medical fields depending on its excellent magnetic properties [4]. The process of oxidation of iron has attracted great attention to form various iron oxides. However, cross-sectional TEM study of oxidation of Fe has been still few due to the challenge in preparing cross-sectional TEM samples and the magnetism issue of iron oxides for TEM imaging. In this paper, we investigate this process directly using SEM and TEM and propose an oxidation mechanism on the basis of the observation.

\section{Experimental details}

First, the high-purity (99.99\%) iron foils were thoroughly rinsed with deionized water followed by ultrasonication in acetone for $5 \mathrm{~min}$. Then, the cleaned iron substrates were put on a substrate heater in the vacuum chamber, and the temperature was monitored using a K-type thermocouple in contact with the heater. The chamber was pumped to a vacuum of about $2 \times 10^{-6}$ Torr, and then filled with 200 Torr oxygen (oxygen purity: 99.999\%). Subsequently, the chamber was sealed, and the iron foil was heated to $600^{\circ} \mathrm{C}$ at a rate of $20^{\circ} \mathrm{C} / \mathrm{min}$ in the oxygen gas. After the 
iron foil was oxidized for $1 \mathrm{~h}$, it was then cooled down in the same oxygen atmosphere to room temperature at a rate of $\sim 10{ }^{\circ} \mathrm{C} / \mathrm{min}$. Morphology and chemical composition of the oxidized samples were investigated using a field emission gun-scanning electron microscope (FEG SEM) FEI Supra 55VP. Cross-sectional specimens of the oxidized iron foil for transmission electron microscopy (TEM) observations were prepared using conventional techniques of mechanical polishing and ion-thinning. The ion-thinning was carried out using Gatan model 691 precision ion polishing system (PIPS). Selected-area electron diffraction (SAED) were carried out using a JEOL JEM 2100F TEM operated at $200 \mathrm{kV}$.

\section{Results and Discussion}

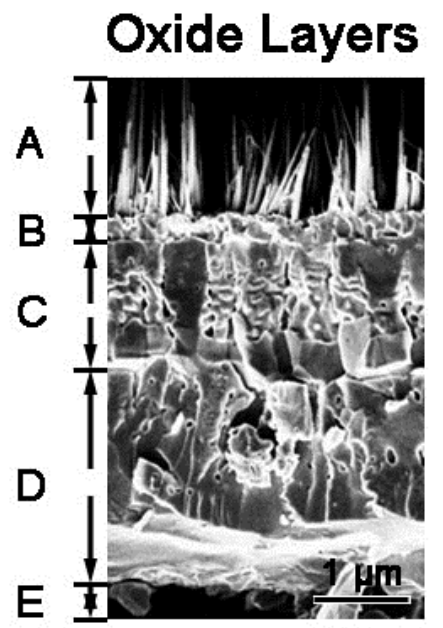

Fig.1 Cross-sectional SEM image of different oxide layers of iron oxidized at $600^{\circ} \mathrm{C}$

Fig. 1 shows a representative cross-sectional SEM image of oxidized iron foil. It can be seen that there are four different layers from the substrate to the surface. Part A is on the top of the surface, which is composed of many nanowires growing from layer $\mathrm{B}$. The thickness of layer $\mathrm{B}$ is just about $0.3 \mu \mathrm{m}$. It is noticed that the composition of layer $\mathrm{C}$ are more regular but those of layer $\mathrm{D}$ are more disordered. Additionally, the thickness of layer D is larger than others and it's about $3 \mu \mathrm{m}$. To identify the crystal structure of the different oxide layers, TEM observations and SAED patterns were used in the following analysis.

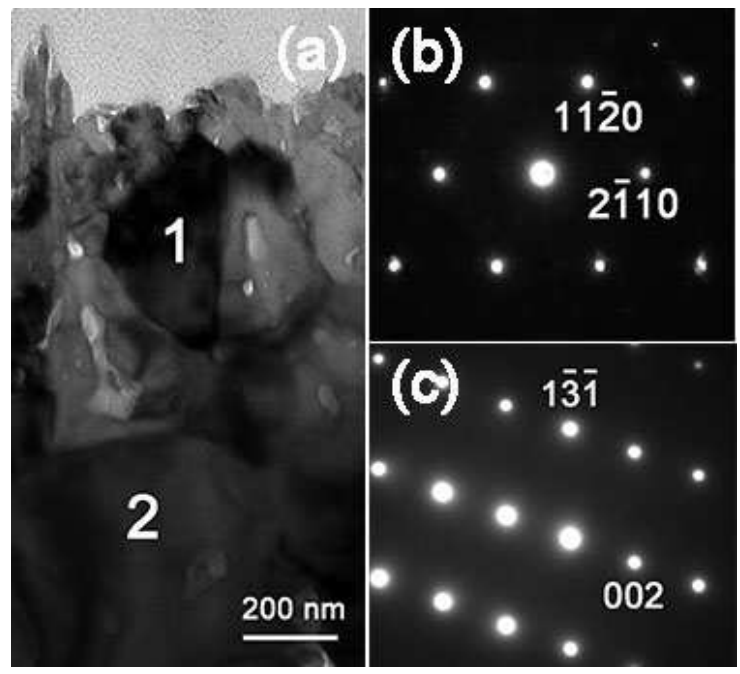

Fig.2 (a) Cross-sectional TEM image showing B, C parts of the Fig.1; (b) SAED pattern taken from grain 1 of (a); (c) SEAD pattern taken from grain 2 of (a) 
Fig.2a is a cross-sectional TEM image which shows layers B, C of the Fig.1. From this image, it can be seen that the size of grain 1 is smaller than grain 2. The SAED patterns (b) and (c) are corresponding to grain 1 and grain 2 marked in Fig.2a, respectively. Fig.2b shows a typical [0001] zone-axis selected area electron diffraction (SAED) pattern taken from grain 1 and the diffraction pattern can be indexed with the $\alpha-\mathrm{Fe}_{2} \mathrm{O}_{3}$ structure $(\mathrm{a}=0.5034 \mathrm{~nm}, \mathrm{c}=1.375 \mathrm{~nm})$. Meanwhile, the SAED pattern (c) can be indexed with the $\mathrm{Fe}_{3} \mathrm{O}_{4}$ structure $(\mathrm{a}=0.839 \mathrm{~nm})$, which is taken along [310] zone-axis of grain 2. On the basis of the analysis, it is revealed that layer $\mathrm{B}$ is $\alpha-\mathrm{Fe}_{2} \mathrm{O}_{3}$ while layer $\mathrm{C}$ is $\mathrm{Fe}_{3} \mathrm{O}_{4}$.

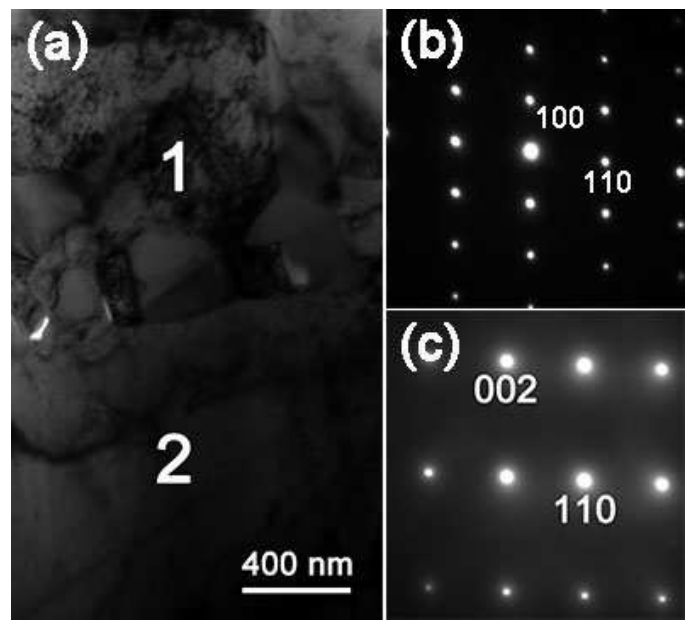

Fig.3 (a) Cross-sectional TEM image showing layer D and E of Fig.1; (b) and (c) SAED patterns corresponding to Part 1 and 2 of (a).

A cross-sectional TEM image showing layers D, E of Fig.1 is also presented as Fig.3a. The SAED patterns (b) and (c) are corresponding to Fig.3a 1 and 2, respectively. Fig.3b shows a typical SAED pattern taken along [001] zone axis of part 1 and the diffraction pattern is indexed with the $\mathrm{FeO}$ structure. The SAED pattern Fig. $3 \mathrm{c}$ can be indexed with the Fe structure $(\mathrm{a}=0.287 \mathrm{~nm})$, which is taken along [110] zone axis of part 2. In fact, layer $\mathrm{E}$ is iron substrate, which is identical to the SAED pattern.

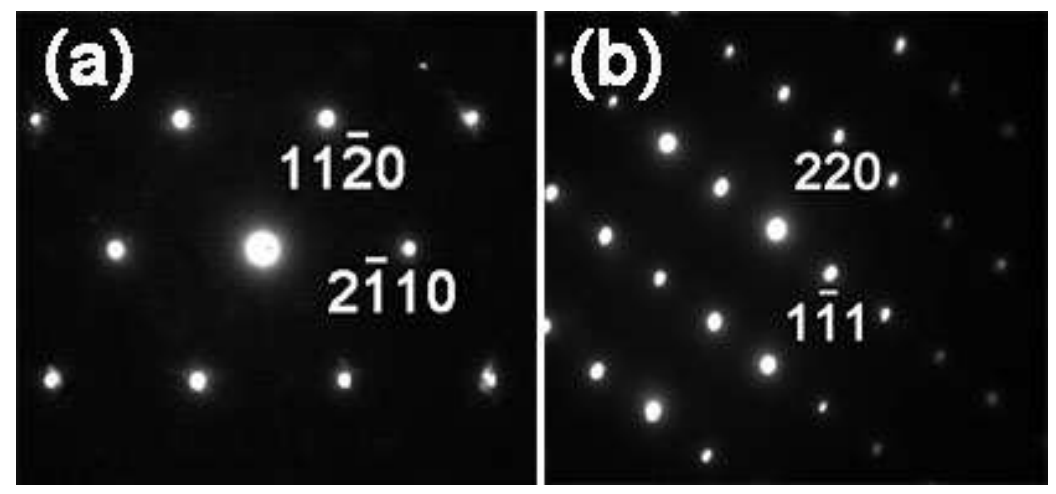

Fig.4 (a) and (b) Different SAED patterns corresponding to $\alpha-\mathrm{Fe}_{2} \mathrm{O}_{3}$ and $\gamma-\mathrm{Fe}_{2} \mathrm{O}_{3}$

$\alpha-\mathrm{Fe}_{2} \mathrm{O}_{3}$ and $\gamma-\mathrm{Fe}_{2} \mathrm{O}_{3}$ structures were observed at the same time depending on their SAED patterns. It is also mentioned and discussed by Cai et al. [5]. Fig.4a is taken along [0001] zone axis, which is indexed with $\alpha-\mathrm{Fe}_{2} \mathrm{O}_{3}$ structure. And Fig.4b can be indexed with the $\gamma-\mathrm{Fe}_{2} \mathrm{O}_{3}$ structure, 
which is taken along [11ㄹ] zone axis. Coexistence of $\alpha-\mathrm{Fe}_{2} \mathrm{O}_{3}$ and $\gamma-\mathrm{Fe}_{2} \mathrm{O}_{3}$ may be depending on the changes of grain size and temperature but the real mechanism is still elusive [6]. $\alpha / \gamma$ transformation of $\mathrm{Fe}_{2} \mathrm{O}_{3}$ is also discussed in other literatures [7].

Depending on our investigations, compositions of different layers were clarified. From iron substrate to its surface, four different layers were identified as $\mathrm{FeO}, \mathrm{Fe}_{3} \mathrm{O}_{4}, \mathrm{Fe}_{2} \mathrm{O}_{3}$ and $\mathrm{Fe}_{2} \mathrm{O}_{3} \mathrm{NWs}_{\text {. }}$ The ratios of $\mathrm{Fe}$ to $\mathrm{O}$ in different iron oxides are 1:1, 1:1.33 (3:4), 1:1.5 (2:3), respectively. It can be seen that the ratio of $\mathrm{Fe}$ to $\mathrm{O}$ decreases closing to the surface. The main reason why the ratio decreases is that oxygen content increases gradually closing to the surface and the content of iron ion is sufficient for different layers. On the basis of the observations, a possible mechanism of the oxidation of iron is proposed. As oxygen concentration increases closing to the surface, iron is oxidized to $\mathrm{FeO}$ firstly; and then $\mathrm{FeO}$ is oxidized to $\mathrm{Fe}_{3} \mathrm{O}_{4}$; finally, $\mathrm{Fe}_{3} \mathrm{O}_{4}$ is oxidized to $\mathrm{Fe}_{2} \mathrm{O}_{3}$ and $\mathrm{Fe}_{2} \mathrm{O}_{3}$ is the most stable iron oxide at ambient conditions.

\section{Conclusions}

In conclusion, it is revealed that there are four different layers from iron substrate to its surface, which is identified as $\mathrm{FeO}, \mathrm{Fe}_{3} \mathrm{O}_{4}, \mathrm{Fe}_{2} \mathrm{O}_{3}$ and $\mathrm{Fe}_{2} \mathrm{O}_{3} \mathrm{NWs}$. The main reason that different layers consist of different iron oxides is the decrease of oxygen content with the increase of depth. Different iron oxide layers develop as oxygen concentration changes. Additionally, $\alpha-\mathrm{Fe}_{2} \mathrm{O}_{3}$ and $\gamma-\mathrm{Fe}_{2} \mathrm{O}_{3}$ structures were observed at the same time but the reason of coexistence is still not clear.

\section{Acknowledgement}

This work was financially supported by the Program of Science and Technology for Higher Education in Shandong Province (Grant no.: J12LA17).

\section{Reference}

[1] Q. Liu, Z.M. Cui, Z. Ma, S.W. Bian, W.G. Song, L.J. Wan, Nanotechnology 18, 385605 (2007)

[2] L. Huo, W. Li, L. Lu, H. Cui, S. Xi, J. Wang, B. Zhao, Y. Shen, Z. Lu, Chem. Mater. 12, 790 (2000)

[3] H. Srivastava, P. Tiwari, A.K. Srivastava, R.V. Nandedkar, J. Appl. Phys. 102, 054303 (2007)

[4] X. Wang, R. Zhang, C. Wu, Y. Dai, M. Song, S. Gutmann, F. Gao, G. Lv, J. Li, X. Li, J. Biomed. Mater. Res. A 80, 852 (2006)

[5] R. Cai, T. Li, Y. Wang, C. Wang, L. Yuan, G. Zhou, J. Nanopart. Res. 14, 1 (2012)

[6] M. Multani, P. Ayyub, Condens. Matter News 1, 25 (1991)

[7] T. Belin, N. Millot, N. Bovet, M. Gailhanou, J. Solid State Chem. 180, 2377 (2007) 
Advances in Applied Science, Engineering and Technology

10.4028/www.scientific.net/AMR.709

\section{Mechanism of the Oxidation of Iron}

10.4028/www.scientific.net/AMR.709.106 